\title{
Functional Impact of Osteosuture in Medial Bilateral Clavicular Physeal Fracture in Teenagers
}

\author{
Rabhi $C^{1,3 *}$, Orfeuvre B ${ }^{1,3}$, Eid $A^{1,3}$, Griffet $\mathbf{J}^{1,3}$, Rabattu PY2,3 and Courvoisier $\mathbf{A}^{1,3}$ \\ ${ }^{1}$ Department of Pediatric Ortopaedic, Universitary Hospital Couple-Enfant, CHU of Grenoble-Alpes, France \\ ${ }^{2}$ Service de Department of Pediatric Surgery, Universitary Hospital Couple-Enfant, CHU of Grenoble-Alpes, France \\ ${ }^{3}$ University of Grenoble-Alpes, France
}

${ }^{\star}$ Corresponding author: Camille Rabhi Department of Pediatric Ortopaedic, Universitary Hospital Couple-Enfant, CHU of Grenoble-Alpes, France; E-mail: CRabhi@chu-grenoble.fr

Received: November 17, 2020; Accepted: November 24, 2020; Published: November 30, 2020

\begin{abstract}
Proximal physeal fracture of the medial clavicular physis is a rare specific injury occurring in the immature skeletal. Several studies describe unilateral cases with posterior or anterior displacement and the following complications (vascular and mediastinal compression). An immediate diagnosis and management are necessary to avoid complications. The clinical diagnostic might be obvious or difficult, pain and swelling in the sternoclavicular joint area, sometimes a deformity and focal tenderness. A chest X-Ray may help and a three-dimensional reconstructed computed tomography scan has to be done to evaluate the lesions before surgery. The imaging is useful to confirm and specify the diagnostic and the displacement. After reviewing the literature of the unilateral clavicular physeal fracture, we can conclude that the ideal management of these injuries has not been well described. An open reduction associated an osteosuture with non-resorbable suture was performed. One-year follow-up, both of them had full recovery without any functional impact or any complains. This management of the proximal physeal fracture of the medial clavicle on children shows an excellent result according our cases and the literature. The purpose of this study is to evaluate the functional impact of osteosuture in medial bilateral clavicular physeal fracture in teenagers after 1-year follow-up. We present 4 cases of proximal physeal fracture of the medial clavicular physis in 2 male-teenagers with bilateral displacement, one posterior and the other asymmetric.
\end{abstract}

\section{Introduction}

Clavicular physeal fracture is an uncommon pediatric fracture [1-9], especially bilateral. The lesion is not the same as in adults, who have a sternoclavicular disjunction. In children, it is a physeal fracture, included in Salter \& Harris classification [5,7,10]. The diagnosis, management and treatment totally differ in adults. These injuries mostly occur during sport activities [8], with high energy trauma, due to a direct force applied to the medial clavicle or an indirect force on the shoulder $[1,3,6,9]$. The clinical diagnostic might be obvious or difficult $[8,10]$, pain and swelling in the sternoclavicular joint area [1], sometimes a deformity, focal tenderness and a clinical instability [2]. Therefore X-Ray and CT scan must be done in order to confirm the diagnosis $[1,3-6,10]$. Three-dimensional reconstructed computed tomography scans may help to evaluate the lesions before surgery $[2,3]$. Several complications $[8,10]$, such as tracheal or vascular compression [11,12], which are revealed by dyspnea, dysphagia or odynophagia $[1,5]$, can be noticed. Because of the risk of complications in retrosternal displacement of the medial clavicular metaphysic [8,9], a surgical treatment has to be performed $[4,5,10,13]$. The purpose of this treatment is different than in adults, the primary instability caused by the fracture will be resolute with the osteosuture and the bone healing. In adults, an arthrodesis is necessary to access the definitive stability of the sterno-clavicular articulation. The aim of this report is to demonstrate the functional impact on the medial bilateral clavicular physeal fracture after 1-year follow-up. This report explains 4 cases of proximal physeal fracture of the medial clavicular physis in two teenage boys treated surgically, one of them suffered from a bilateral posterior displacement of clavicular physeal fracture, and the other one, an asymmetric displacement clavicular physeal fracture.

\section{Materials and Methods}

In our center, we received 4 cases of proximal physeal fracture of the medial clavicular physis in two teenage boys. One of them, a 13-year-old skier, presented a bilateral proximal physeal fracture of the medial clavicular physis with a posterior displacement. He complained about dysphonia, dysphagia and dizziness. Initial radiography of the right clavicle was suspicious. A CT scan was performed finding a left physeal fracture with posterior (Salter and Harris I) and a right physeal fracture with posterior displacement (Salter and Harris II) associated with a 4 -cm hematoma. The other one, a 15 -year-old boy sustained a high-energy trauma, presented a bilateral proximal physeal fracture of the medial clavicular physis with an asymmetric displacement. A chest X-Ray was performed and wasn't contributive (Figure 1). The CT-scan showed a left physeal fracture with posterior displacement (Salter and Harris I) and a right physeal fracture with anterior (Salter and Harris I) displacement. The diagnosis was uncertain about the right injury but confirmed intraoperatively because of the clinical instability (Figure 2). 


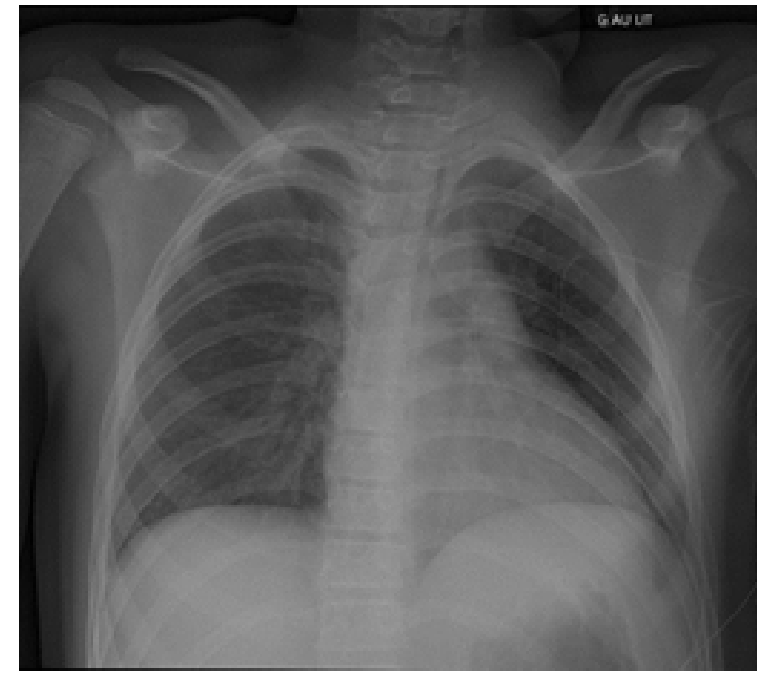

Figure 1: Chest X-Ray.
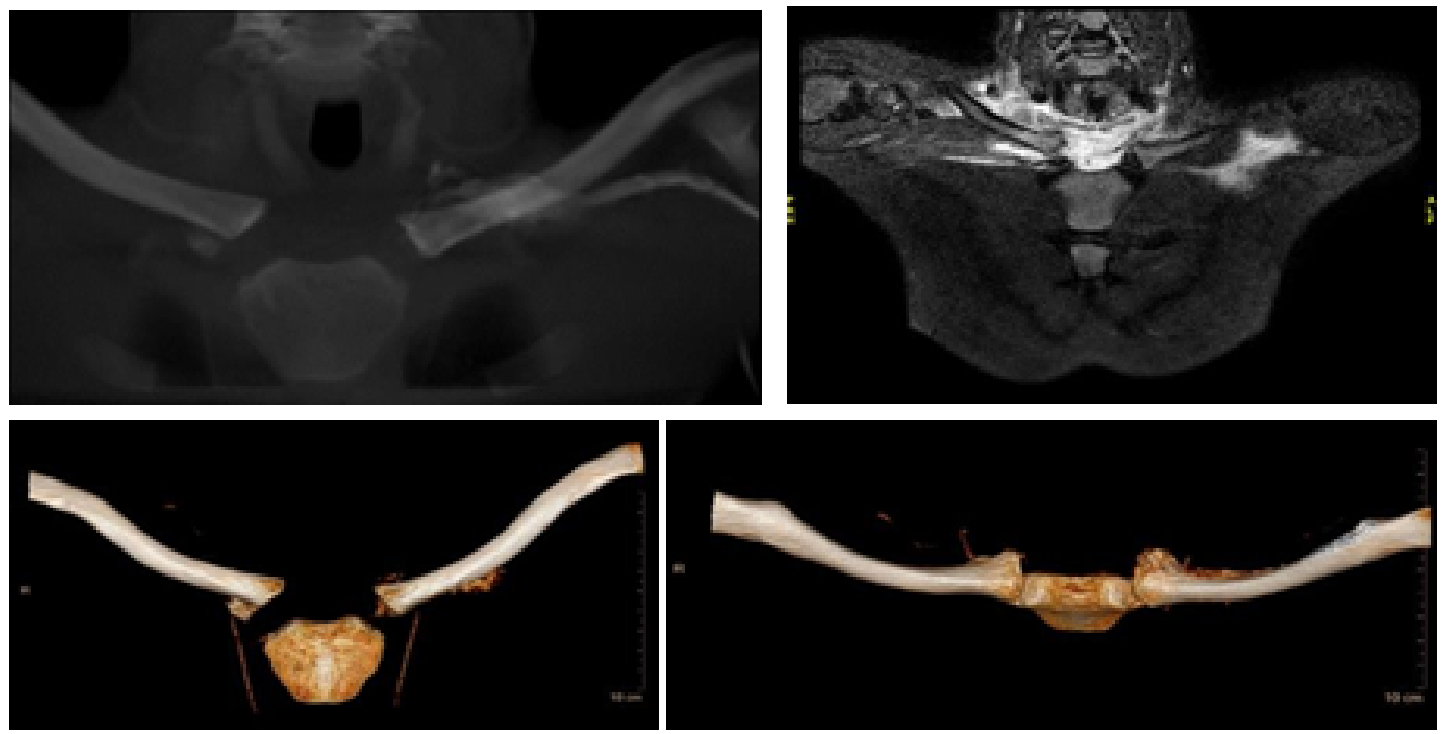

Figure 2: Frontal and three-dimensional reconstructed computed tomography scans confirm the diagnosis of a left physeal fracture (Salter and Harris I) and a right physeal fracture (Salter and Harris II) of the medial clavicular physis.
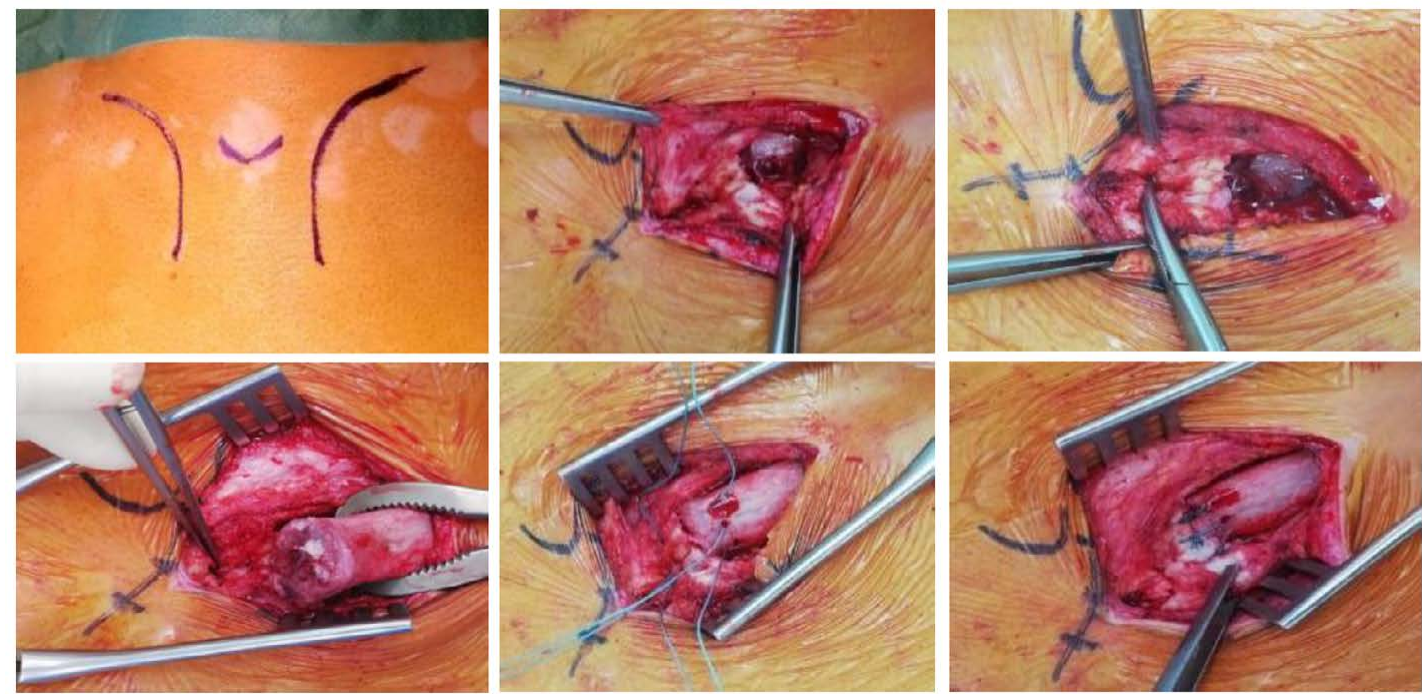

Figure 3: Drawing of the incision and intraoperatively seeings showing the different steps. 


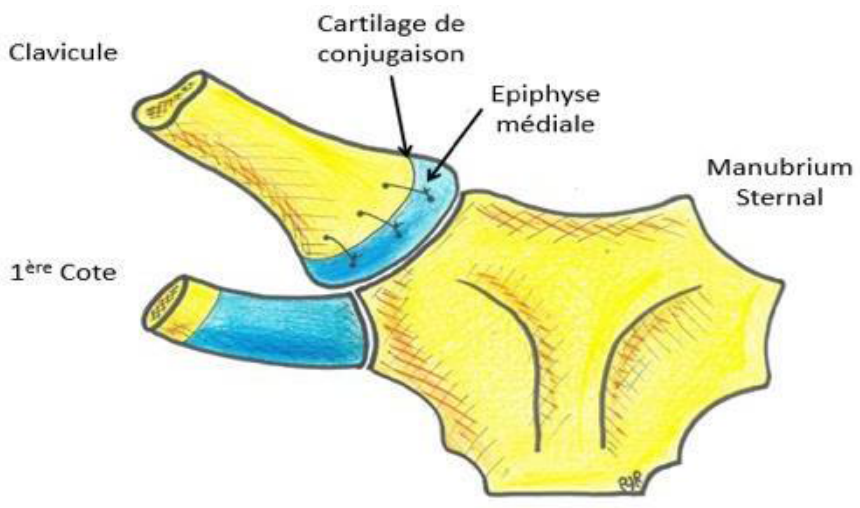

Figure 4: Schematic view of the osteosuture.

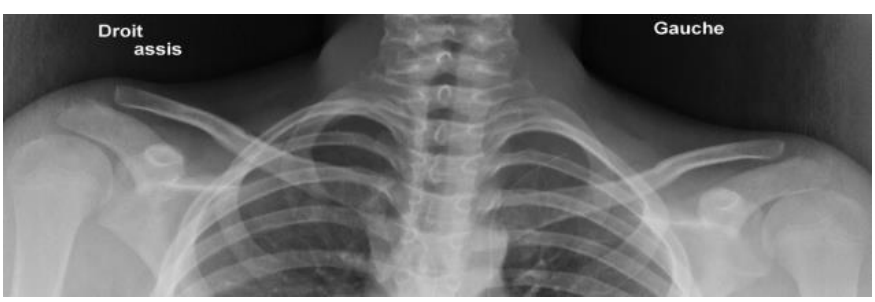

Figure 5: Chest X-Ray non-contributory.
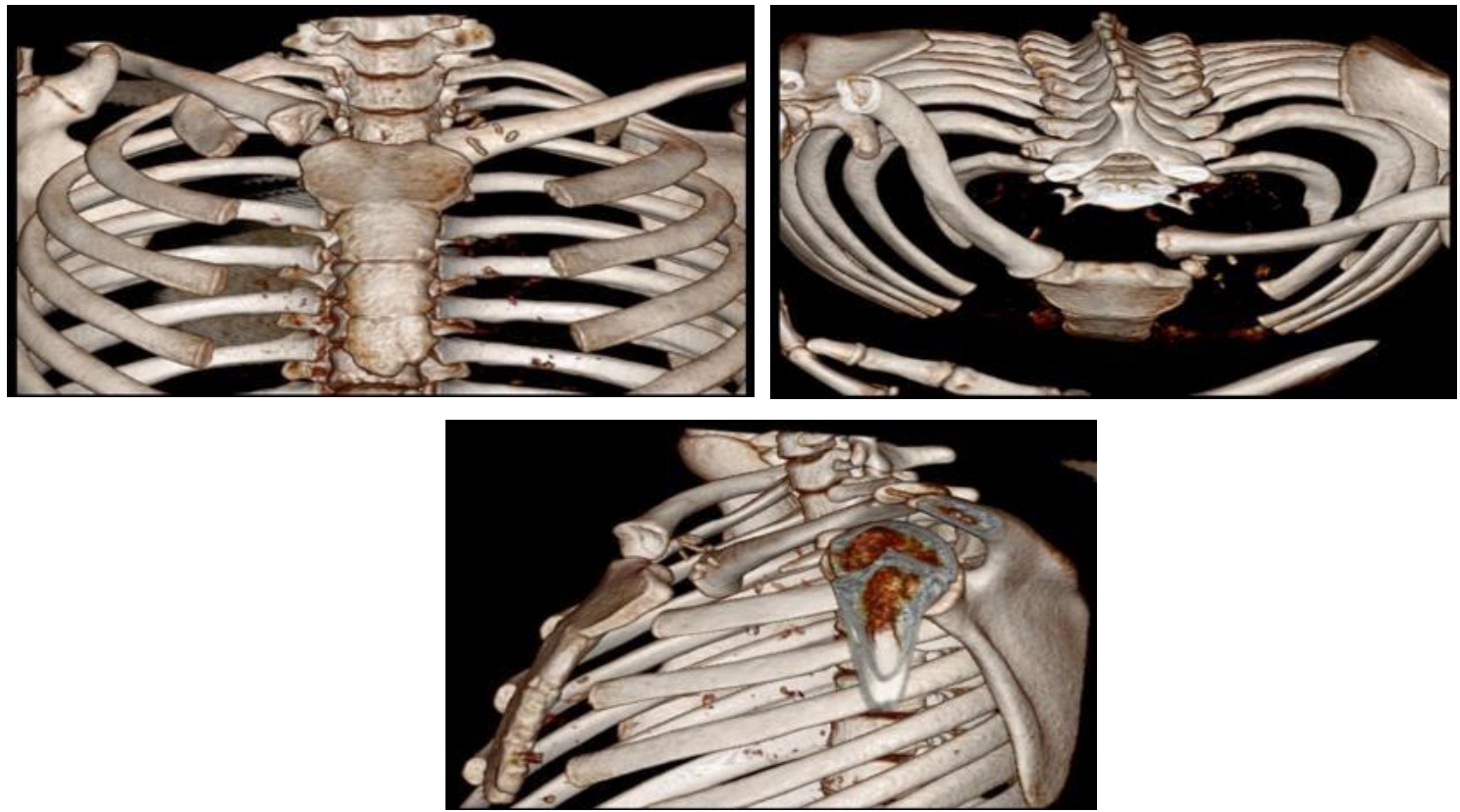

Figure 6: Preoperative three-dimensional reconstructed computed tomography scans show a left physeal fracture (Salter and Harris I) and a right anterior physeal fracture (Salter and Harris I) of the medial clavicular physis.
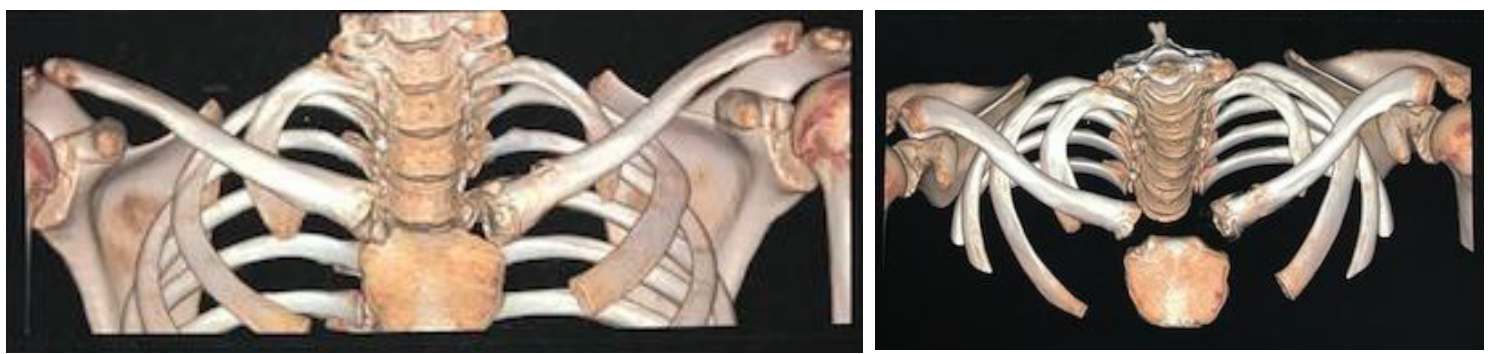

Figure 7: 6 weeks post-operative three-dimensional reconstructed computed tomography scans. 


\section{Discussion}

The primary purpose of this study is to evaluate the functional prognostic of a displaced physeal clavicular fracture after a surgical treatment. The clavicular physeal fracture concern the pediatric population mostly the teenagers with an average of 13 year-old $(0$; 23) (Table 1). Usually it occurs during sports activities after a direct fall on the shoulder [2-5]. In the first place, swelling and pain in the

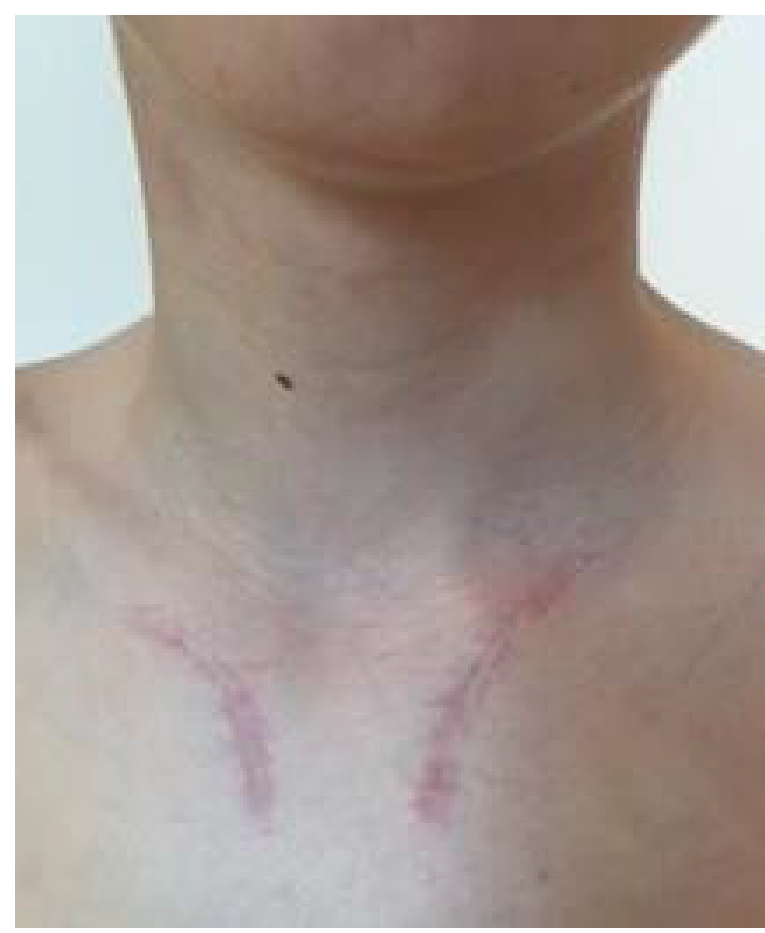

Figure 8: Scars 4 months post-operative. area of the sternoclavicular joint can be noticed with a limitation of the shoulder movements and with the attitude of the upper limb's traumatism [6,7].

According the literature, many patients presented immediate complications such as dysphagia [7,12], dyspnea or vascular compression $[9,13,15,16]$. One of our patient complained about dyspnea and dysphonia that were resolute after a surgical treatment. To avoid complications in the retrosternal structures by either the instable fragment or callus formation, an immediate surgical treatment has to be attempted $[1,11]$. In adults as in children, the risk of complications is the same due to the displacement and the compression.

Several authors described $[7,11,12]$, sometimes this kind of injuries can be missed in the first place. The recurrence of the pain with an initial clinical exam subtle and an inadequate imaging can lead to a tardive diagnosis [12]. A shortening of the acromioclavicular distance may help to diagnose the fracture but can be less specific when the both clavicles are injured. The position of the clavicular epiphysis has to be found to specify the diagnosis. A clinical instability can reveal a reduced medial clavicular physeal fracture with a normal tomography scan. Despite the delayed diagnosis none of their patients present any functional complication $[7,12]$. Intraoperatively, the diagnosis can be more accurate than the initial imaging could reveal [7]. The difference between dislocation and physeal fracture can be determine intraoperatively [7]. The type of the fracture in the Salter \& Harris classification $[2,5,7]$ can be adjust during the surgery. Surgery is the only way to confirm the definitive diagnosis and allow the most appropriate treatment for the patient. Many unilateral cases are described in the literature with diverse treatment: non operative [15], closed reduction [6,7,13] or ORIF with osteosuture [2-5,7]. Siebenmann published a case series and

Table 1: Review of the literature.

\begin{tabular}{|c|c|c|c|c|c|}
\hline Author, year & $\mathbf{n}$ & Age & Displacement & Treatment & Complications \\
\hline \multirow{2}{*}{ Gobet et al. 2004} & 3 & $6-10$ & Ant & 3 ORIF (Osteosuture) & Dysphagia (2) \\
\hline & 3 & $8-15$ & Post & 2 closed reduction +1 ORIF (Osteosuture) & Dysphagia (2) \\
\hline Laffosse et al. 2010 & 13 & $15-20$ & Post & $\begin{array}{l}13 \text { ORIF (5 failure of closed reduction/Different } \\
\text { techniques) }\end{array}$ & Dysphagia (3) \\
\hline Tennent et al. 2012 & 7 & $14-19$ & Post & 7 ORIF (Osteosuture) & Dysphagia(2)/Dyspnea(6) \\
\hline Garg et al. 2012 & 1 & 12 & Post & 1 ORIF (Osteosuture) & $\mathrm{X}$ \\
\hline \multirow{2}{*}{ Gil-Albarova et al. 2012} & 3 & $11-13$ & Ant & 2 ORIF (Osteosuture) + 1 Gilchrist & $\mathrm{x}$ \\
\hline & 1 & 11 & Post & 1 closed reduction & $\mathrm{x}$ \\
\hline Lee et al. 2014 & 20 & $13-18$ & Post & $\begin{array}{l}\text { 2closedreduction+18ORIF (Osteosuture) } \\
\text { (2 failure of closed reduction) }\end{array}$ & $\begin{array}{l}\text { Mediastinal compression (6) (Dysphagia, } \\
\text { odynophagia) }\end{array}$ \\
\hline Ozer et al. 2014 & 1 & 16 & Post & 1 closed reduction & Dyspnea Left brachiocephalic vein compression \\
\hline Tepolt et al. 2014 & 6 & $7-17$ & Post & 6 ORIF (Osteosuture) (2 failure) & Dysphagia + Dyspnea \\
\hline \multirow{2}{*}{ Kassé et al. 2016} & 3 & $0-17$ & Ant & 1 ORIF (Osteosuture) +2 orthopedics & $\mathrm{x}$ \\
\hline & 3 & $16-19$ & Post & $\begin{array}{l}3 \text { ORIF ( } 1 \text { crossed pins }+1 \text { excision } 1 / 3 \text { internal } \\
\text { clavicle with osteosuture }+1 \text { osteosuture) }\end{array}$ & Odynophagia (1) Vascular compression (1) \\
\hline Beckmann et al. 2016 & 1 & 15 & Post & 1 ORIF ( 1 failure of closed reduction) & $\mathrm{X}$ \\
\hline Elmekkaoui et al. 2011 & 1 & 16 & Ant (Salter II) & 1 ORIF (Osteosuture + 1 pin) & $\mathrm{X}$ \\
\hline Deganello et al. 2012 & 1 & 13 & Post & 1 ORIF (Osteosuture) & $\mathrm{x}$ \\
\hline Emms et al. 2002 & 1 & 23 & Post (Salter II) & Excision of the first rib & Subclavian vein compression \\
\hline
\end{tabular}


review of the literature about the management of epiphysiolysis type Salter and Harris I of the medial clavicle with posterior displacement [1]. He recommends an open reduction and fixation (ORIF) of the injury with posterior displacement. The term "epiphysiolysis" [1] is maladapted to characterize the lesion because there isn't a lysis of the physis but a traumatism of the physis as describe by Salter and Harris. In our case, open reduction and osteosuture were performed bilaterally even if, in one of them, the displacement was anterior. This is an instable lesion so the orthopedic treatment is inadequate. This technique was used to avoid an asymmetric result and in order to have a good esthetic result. This treatment is easy to realize, affordable (surgical suture material mostly) and with excellent results. It appears to be important to evaluate the functional prognostic of this injury in the follow-up $[7,13]$. Our patients reach a total of 100/100 after 1-year follow-up with the DASH Score [14]. Mostly return to sports activities between 3 months and a 1 year of recovery $[1,3,4]$ without any complication reported. Esthetic complications can be reported such as hypertrophic or keloid scars where a surgical revision can be useful $[7,15]$. None of our patients complain of their scars.

\section{Conclusion}

This study and literature review demonstrate that a quick surgical treatment of the bilateral clavicular physeal fracture with anterior or posterior displacement has to be done. We highly recommend an ORIF with osteosuture using non resorbable sutures to avoid sequels and hoping a full recovery with a resumption of the sports activities. A thoracic three-dimensional reconstructed computed tomography scan has to be realize to define the lesion. This diagnosis is underreported because this fracture can be occult on imaging. Therefore, all skeletally immature patients with suspected sternoclavicular joint injury have to be carefully examined and especially the signs of complications such as vascular or mediastinal compression. The management of the physis fracture of the medial clavicle totally differ from the management of the sternoclavicular disjunction on the adult population, this is a specific diagnosis, treatment and recovery. The primary instability caused by the fracture will be resolute with the osteosuture and the bone healing. In adults, an arthrodesis is necessary to access the definitive stability of the sterno-clavicular articulation.

\section{References}

1. Siebenmann C, Ramadani F, Barbier G, Gautier E, Vial P (2018) Epiphysiolysis Type Salter I of the Medial Clavicle with Posterior Displacement: Case Series and Review of the Literature. Case Rep Orthop 4986061. [crossref]

2. Beckmann N, Crawford L (2016) Posterior sternoclavicular Salter-Harris fracturedislocation in a patient with unossified medial clavicle epiphysis. Skeletal Radiol 45: 1123-7. [crossref]

3. Deganello A, Meacock L, Tavakkolizadeh A, Sinha J, Elias DA (2012) The value of ultrasound in assessing displacement of a medial clavicular physeal separation in an adolescent. Skeletal Radiol [crossref]

4. El Mekkaoui MJ, Sekkach N, Bazeli A, Faustin JM (2011) Proximal clavicle physeal fracture -separation mimicking an anterior sterno-clavicular dislocation. Orthop Traumatol Surg Res 97: 349-352.

5. Garg S, Alshameeri ZA, Wallace WA (2012) Posterior sternoclavicular joint dislocation in a child: a case report with review of literature. J Shoulder Elbow Surg 21: 11-16. [crossref]

6. Gil-Albarova J, Rebollo-González S, Gómez-Palacio VE, Herrera A (2013) Management of sternoclavicular dislocation in young children: considerations about diagnosis and treatment of four cases. Musculoskelet Surg 97: 137-143. [crossref]

7. Gobet R, Meuli M, Altermatt S, Jenni V, Willi UV (2004) Medial clavicular epiphysiolysis in children: the so-called sterno-clavicular dislocation. Emerg Radiol 10: 252-255. [crossref]

8. Laffosse J-M, Espié A, Bonnevialle N, Mansat P, Tricoire J-L, et al. (2010) Posterior dislocation of the sternoclavicular joint and epiphyseal disruption of the media clavicle with posterior displacement in sports participants. J Bone Joint Surg Br 92: 103-109. [crossref]

9. Tepolt F, Carry PM, Heyn PC, Miller NH (2014) Posterior sternoclavicular joint injuries in the adolescent population: a meta-analysis. Am J Sports Med. 42: 2517-2524.

10. Chaudhry S (2015) Pediatric Posterior Sternoclavicular Joint Injuries: J Am Acad Orthop Surg 23: 468-475. [crossref]

11. Lee JT, Nasreddine AY, Black EM, Bae DS, Kocher MS (2014) Posterior Sternoclavicular Joint Injuries in Skeletally Immature Patients: J Pediatr Orthop 34: 369-375. [crossref]

12. Özer UE, Yalçin MB, Kanberoglu K, Bagatur AE (2014) Retrosternal displacement of the clavicle after medial physeal fracture in an adolescent: MRI. J Pediatr Orthop B 23: 375-378. [crossref]

13. Tennent TD, Pearse EO, Eastwood DM (2012) A new technique for stabilizing adolescent posteriorly displaced physeal medial clavicular fractures. J Shoulder Elbow Surg 21: 1734-1739. [crossref]

14. HAS. DASH Score. 2000. Available at: https://www.s-f-t-s.org/images/stories/ documentations/EPAULE_SCORE_DASH.pdf. Accessed November 15, 2019.

15. Kassé AN, Mohamed Limam SO, Diao S, Sané JC, Thiam B, et al. (2016) [Fractureseparation of the medial clavicular epiphysis: about 6 cases and review of the literature] Pan Afr Med J 25: 19 [crossref]

16. Emms NW, Morris AD, Kaye JC, Blair SD (2002) Subclavian vein obstruction caused by an unreduced type II Salter Harris injury of the medial clavicularphysis. J Shoulder Elbow Surg 11: 271-273.

\section{Citation:}

Rabhi C, Orfeuvre B, Eid A, Griffet J, Rabattu PY, et al. (2020) Functional Impact of Osteosuture in Medial Bilateral Clavicular Physeal Fracture in Teenagers. J Neurol Neurocrit Care Volume 3(4): 1-5. 